\title{
A Design of Experiments Investigation of Offset Streams for Supersonic Jet Noise Reduction
}

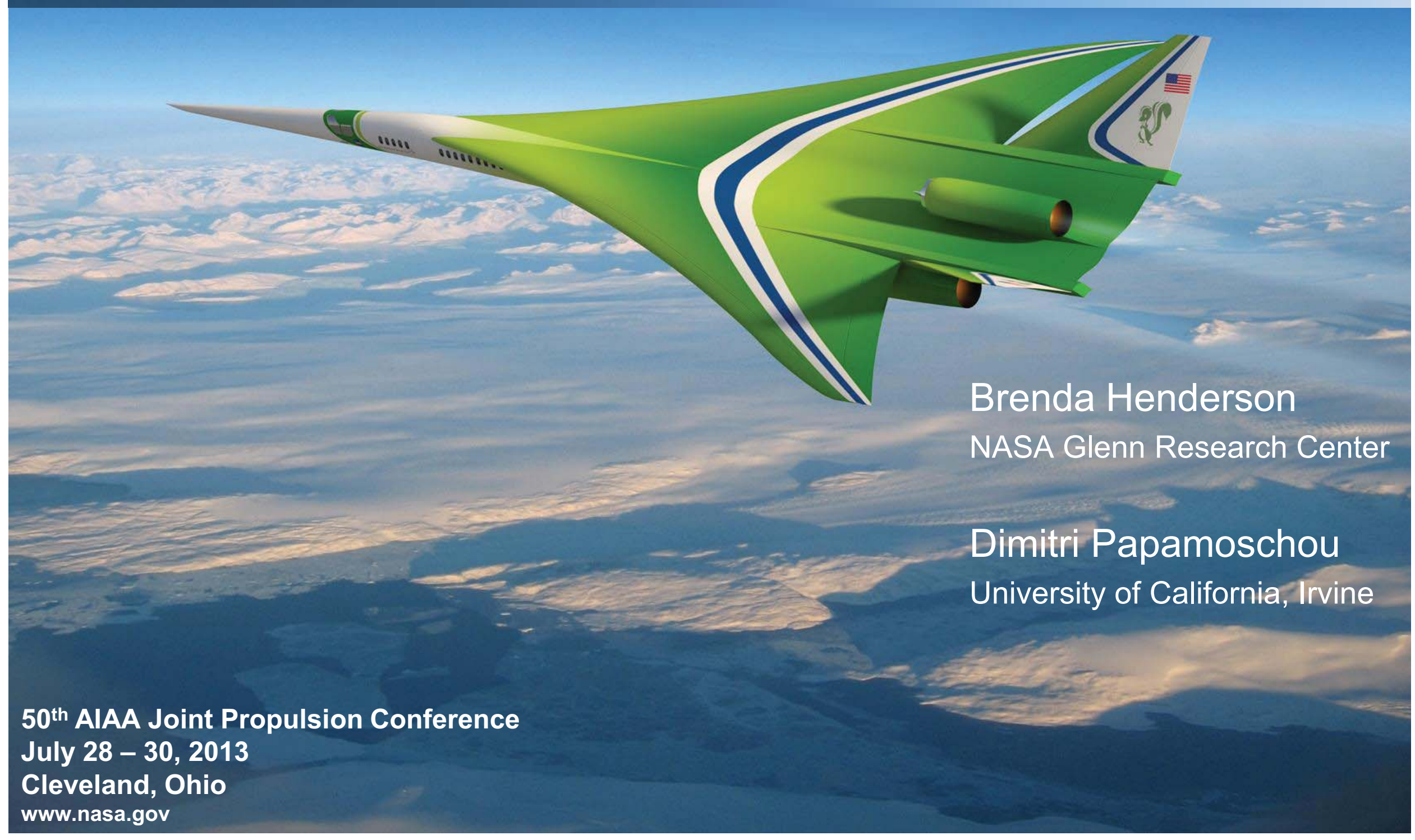




\section{Purpose of Airfoils}

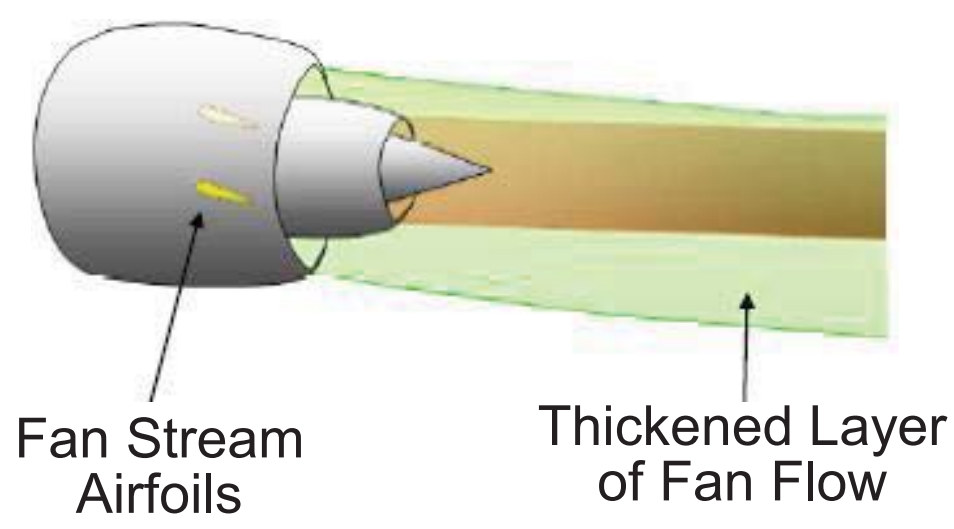

\section{Offset fan stream relative to core stream}

- Lengthen secondary potential core on observation side of jet

- Reduce convective Mach number of the instability waves

- Reduce acoustic radiation associated with instability waves

- Alter turbulent kinetic energy 


\section{Objectives}

- Perform a Design of Experiments (DoE) over large parametric range

- Using results of DoE, develop noise reduction models

- Models will be used in NASA's Aircraft Noise Prediction Program (ANOPP)

- Predictive capability will be used in future CFD study to understand flow-field leading to minimum noise 


\section{Parametric Study}

\section{Observation Side}

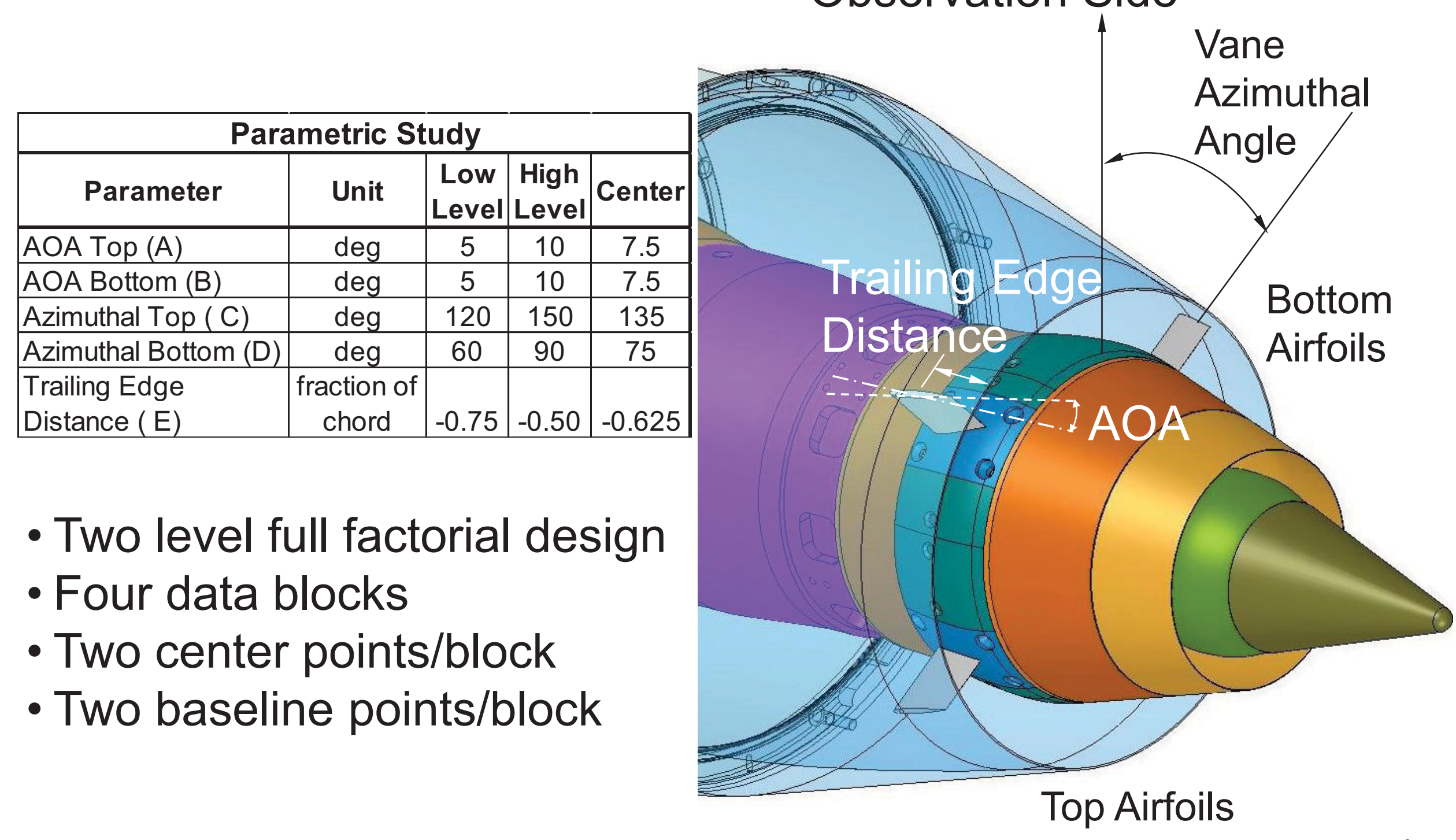




\section{Cycle Points}

\begin{tabular}{|c|c|c|c|c|c|}
\hline Cycle & $\mathbf{M}_{\mathbf{p}}$ & $\mathbf{U}_{\mathbf{p}}(\mathbf{m} / \mathbf{s})$ & $\mathbf{M}_{\mathbf{s}}$ & $\mathbf{U}_{\mathbf{s}}(\mathbf{m} / \mathbf{s})$ & $\mathbf{B P R}$ \\
\hline 01 & 0.84 & 432 & 0.79 & 274 & 1.83 \\
02 & 1.00 & 530 & 0.96 & 333 & 1.91 \\
03 & 1.13 & 606 & 1.09 & 378 & 1.94 \\
04 & 1.19 & 640 & 1.14 & 397 & 1.96 \\
\hline
\end{tabular}

- Bypass ratio two nozzle system

- Cycle points based on system studies 


\section{Experiments}
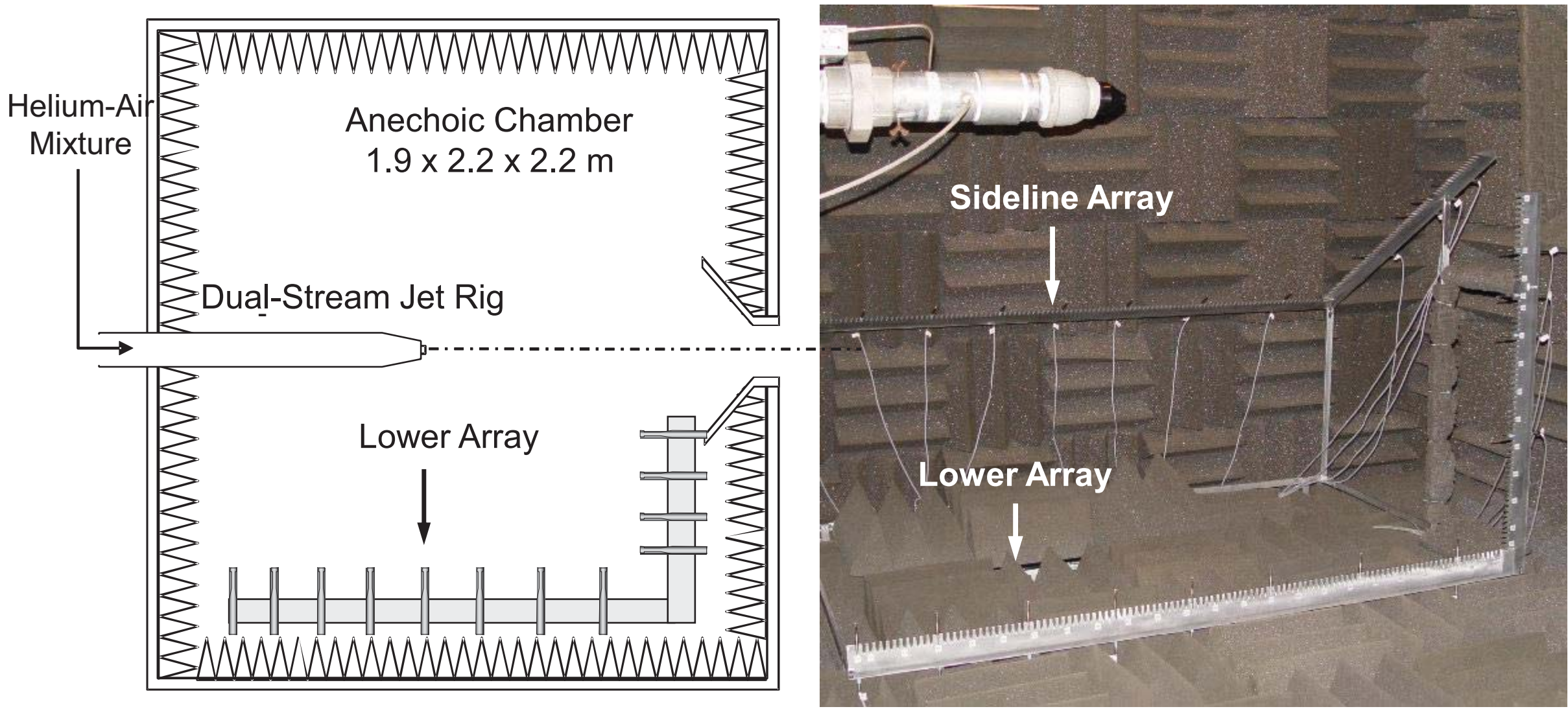

University of California, Irvine's Aeroacoustics Facility 


\section{Narrowband Results - Cycle 04}

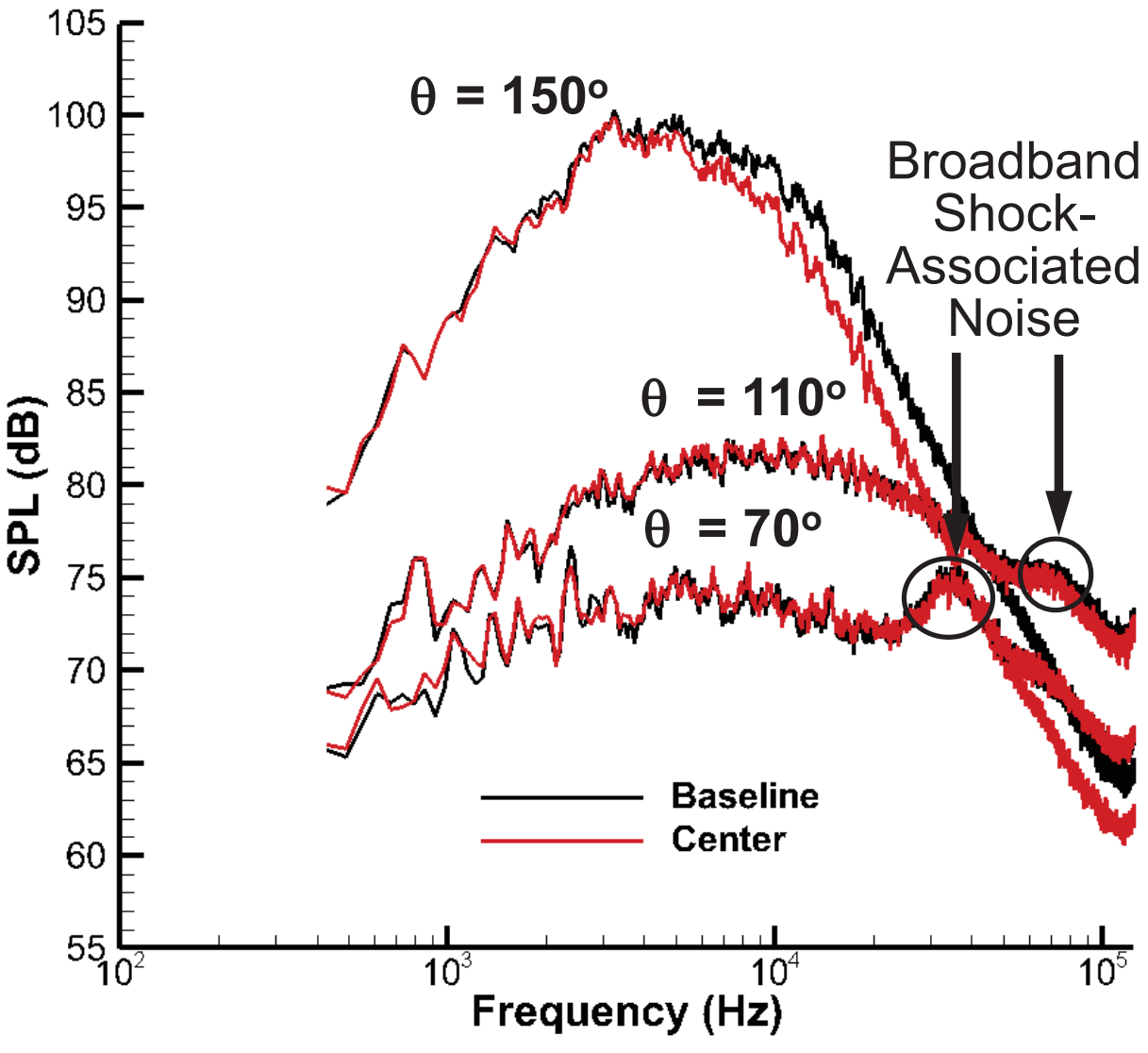

Sideline Array

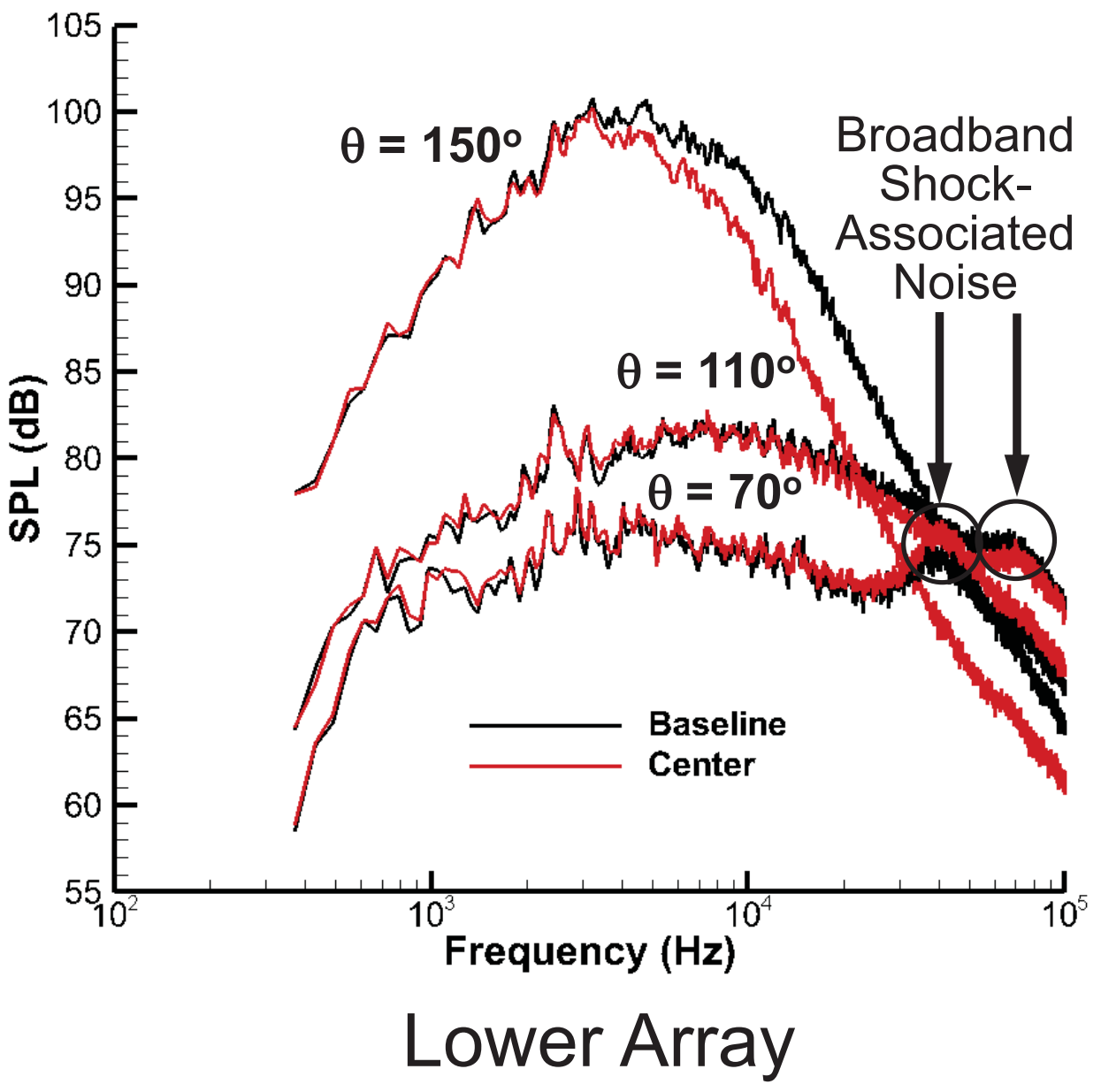




\section{Narrowband Results - Sideline Array}

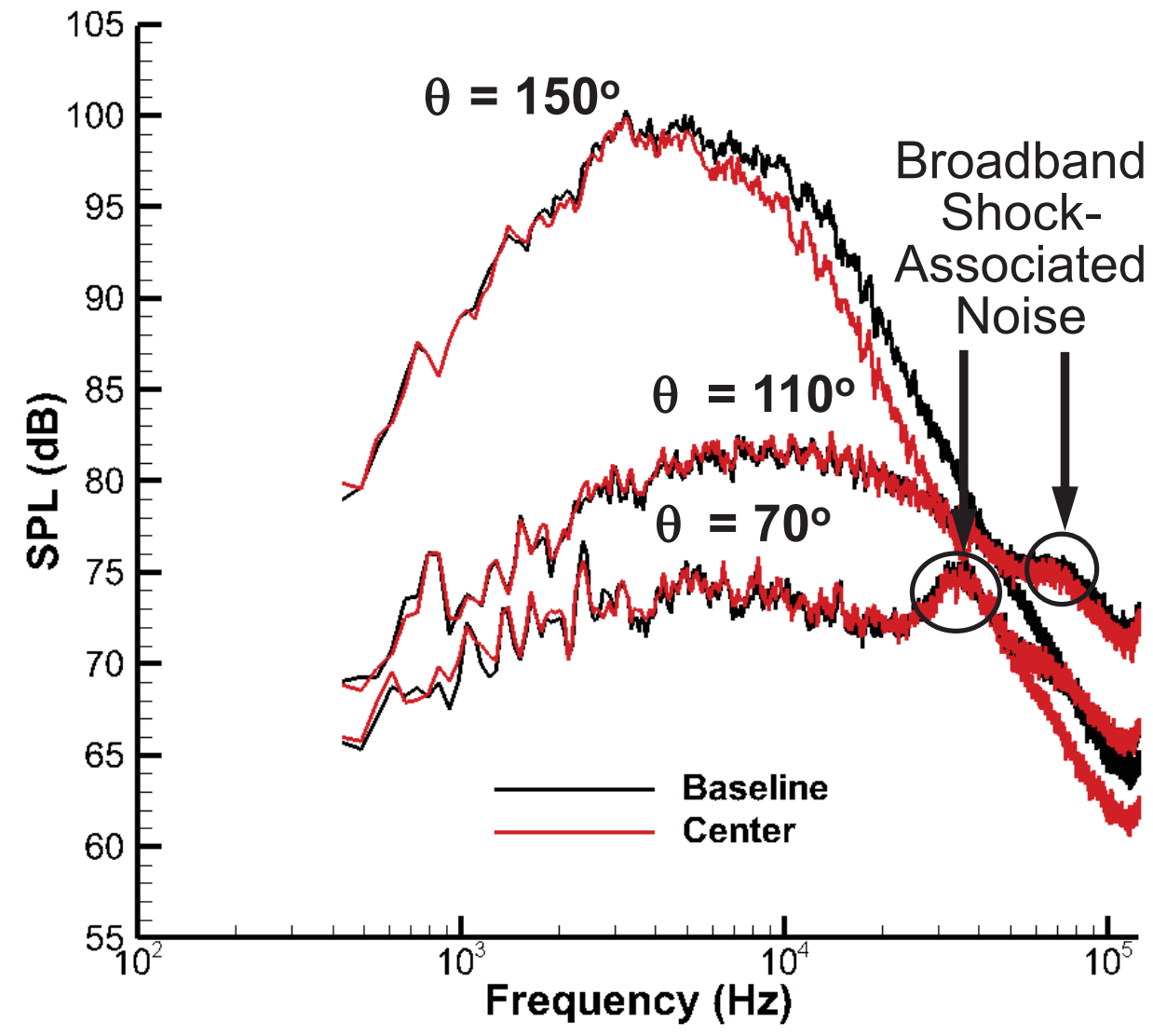

Cycle 04

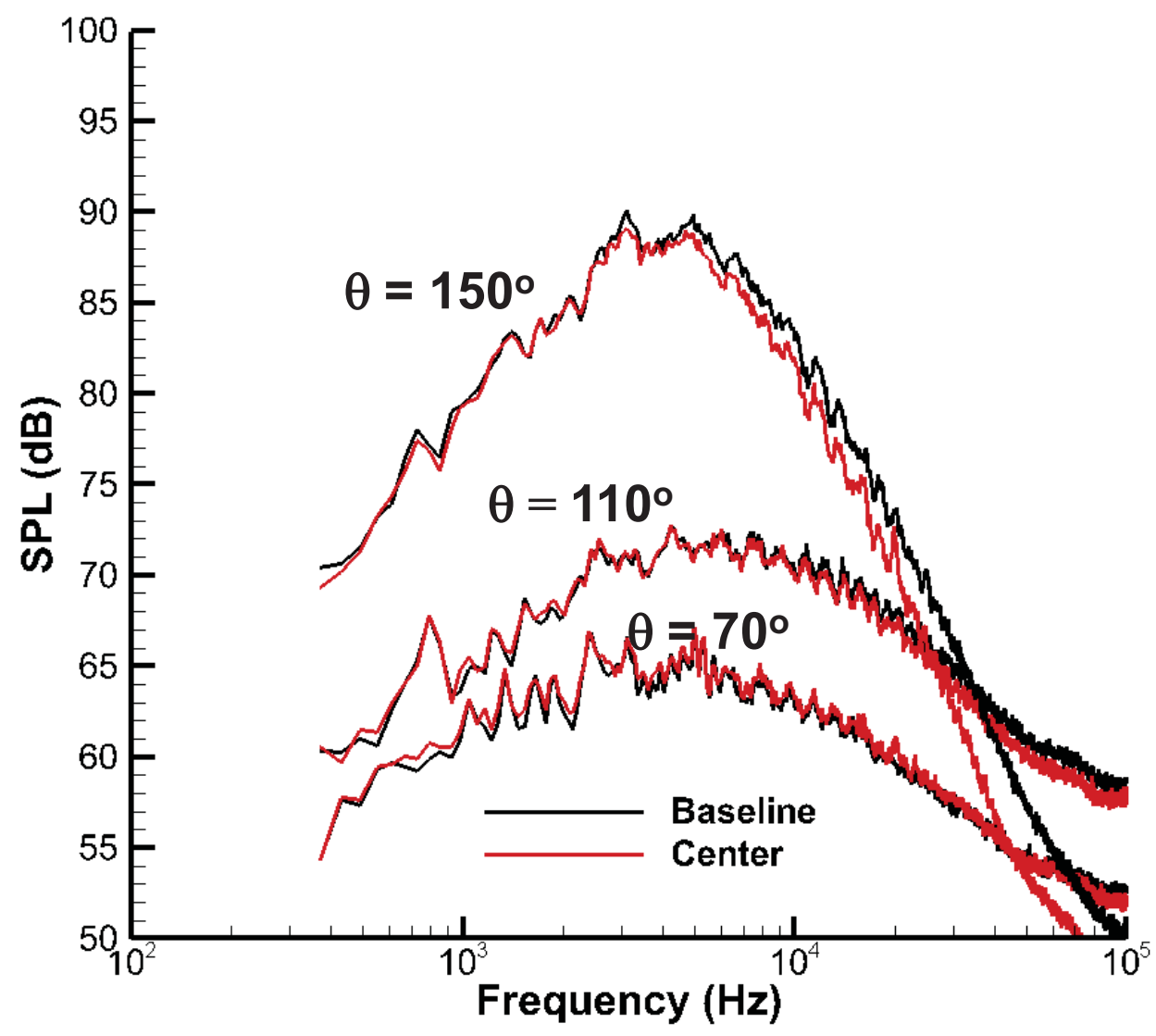

Cycle 01 


\section{Cycle Points}

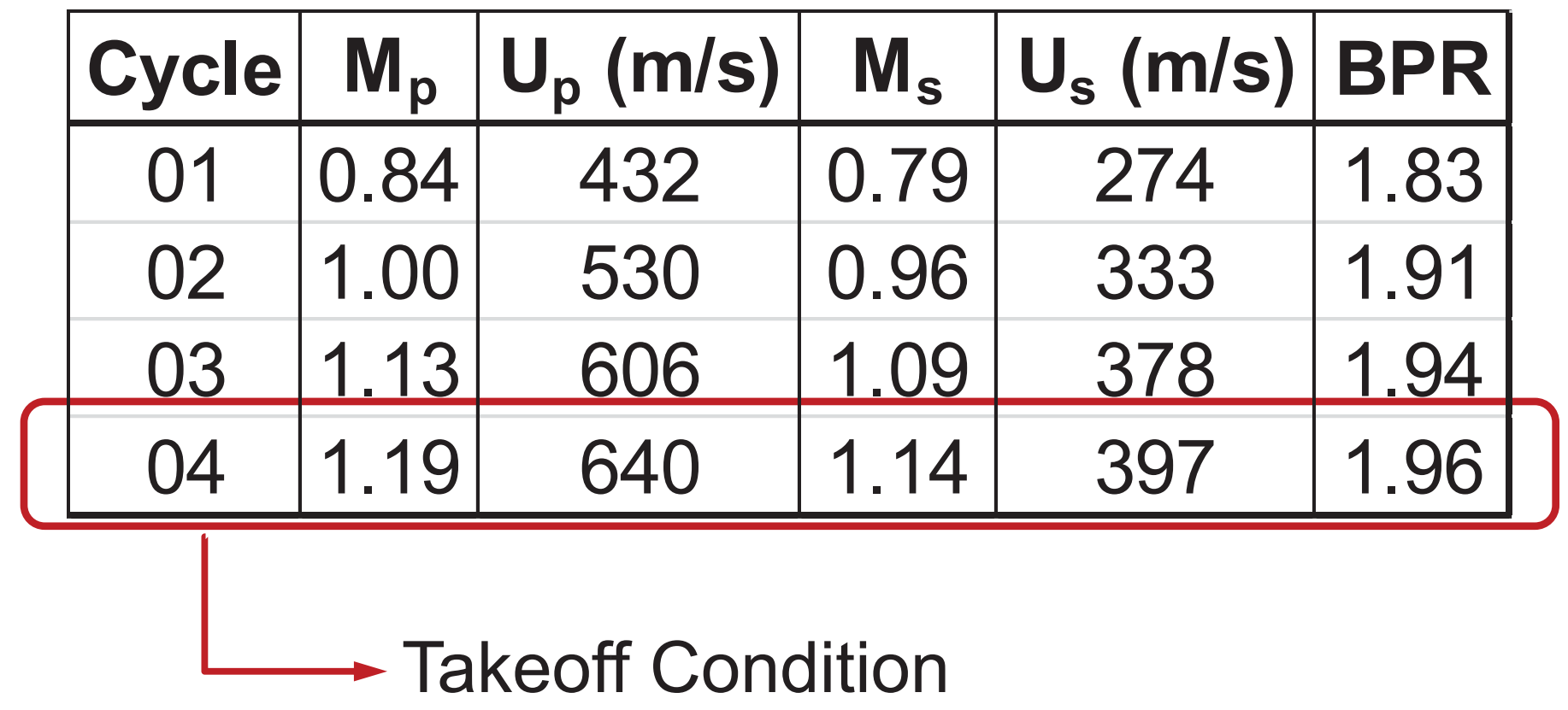




\section{Model}

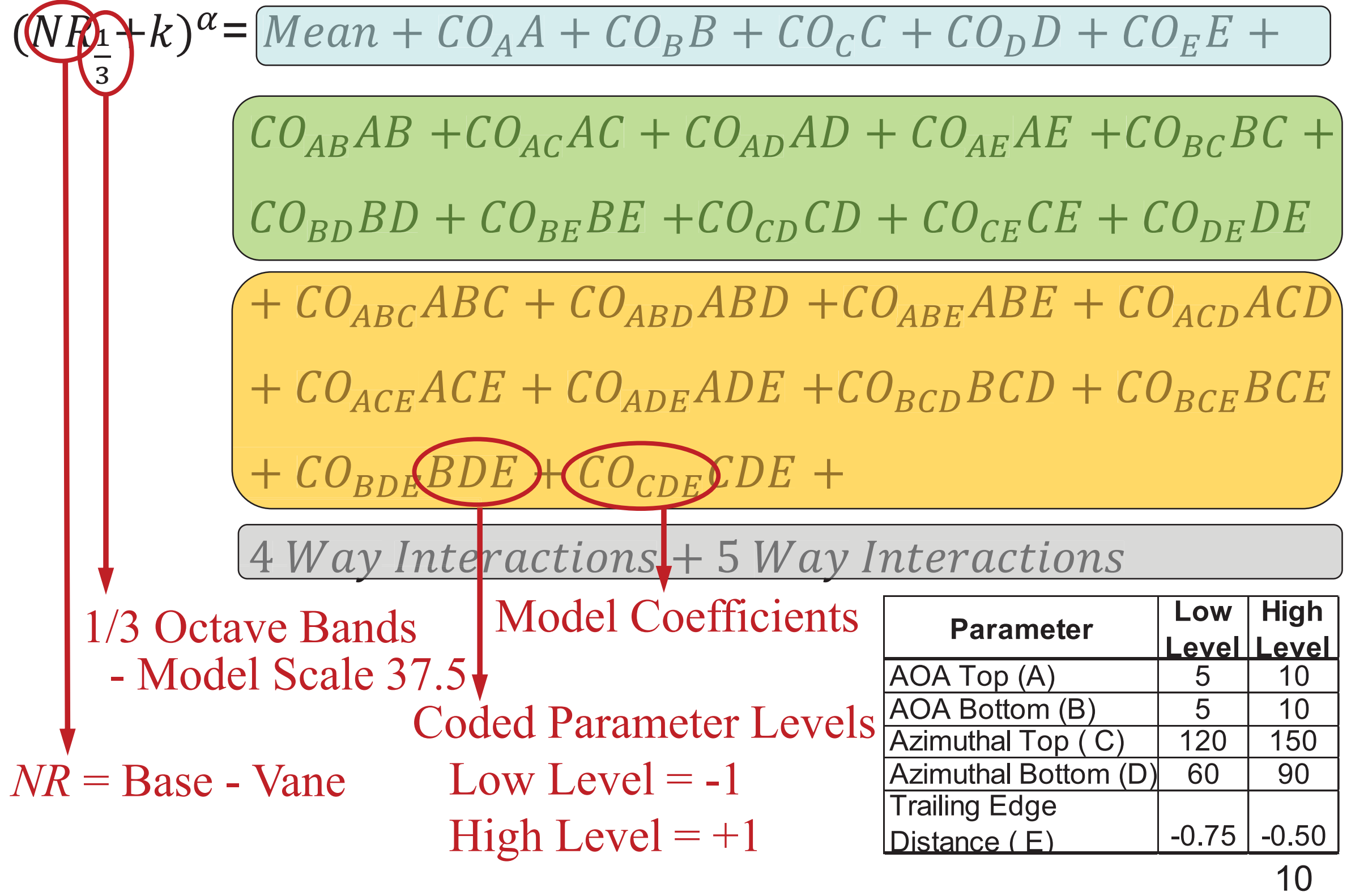




\section{1/3 Octave Band Results - Lower}

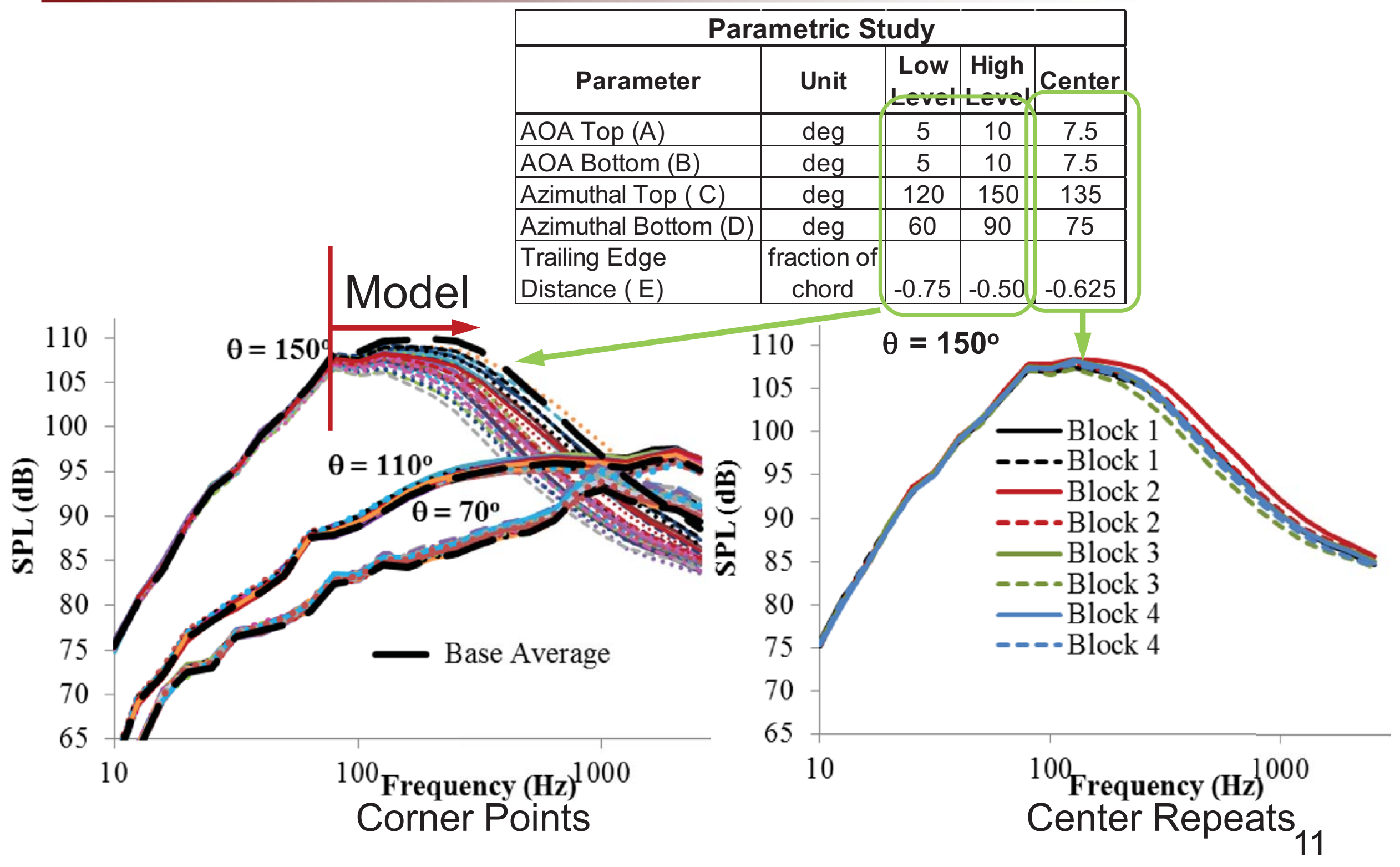




\section{Sideline Model - Peak Polar Angle}

\begin{tabular}{|l|c|c|}
\hline \multicolumn{1}{|c|}{ Parameter } & $\begin{array}{c}\text { Low } \\
\text { Level }\end{array}$ & $\begin{array}{c}\text { High } \\
\text { Level }\end{array}$ \\
\hline AOA Top (A) & 5 & 10 \\
\hline AOA Bottom (B) & 5 & 10 \\
\hline Azimuthal Top (C) & 120 & 150 \\
\hline Azimuthal Bottom (D) & 60 & 90 \\
\hline $\begin{array}{l}\text { Trailing Edge } \\
\text { Distance (E) }\end{array}$ & -0.75 & -0.50 \\
\hline
\end{tabular}

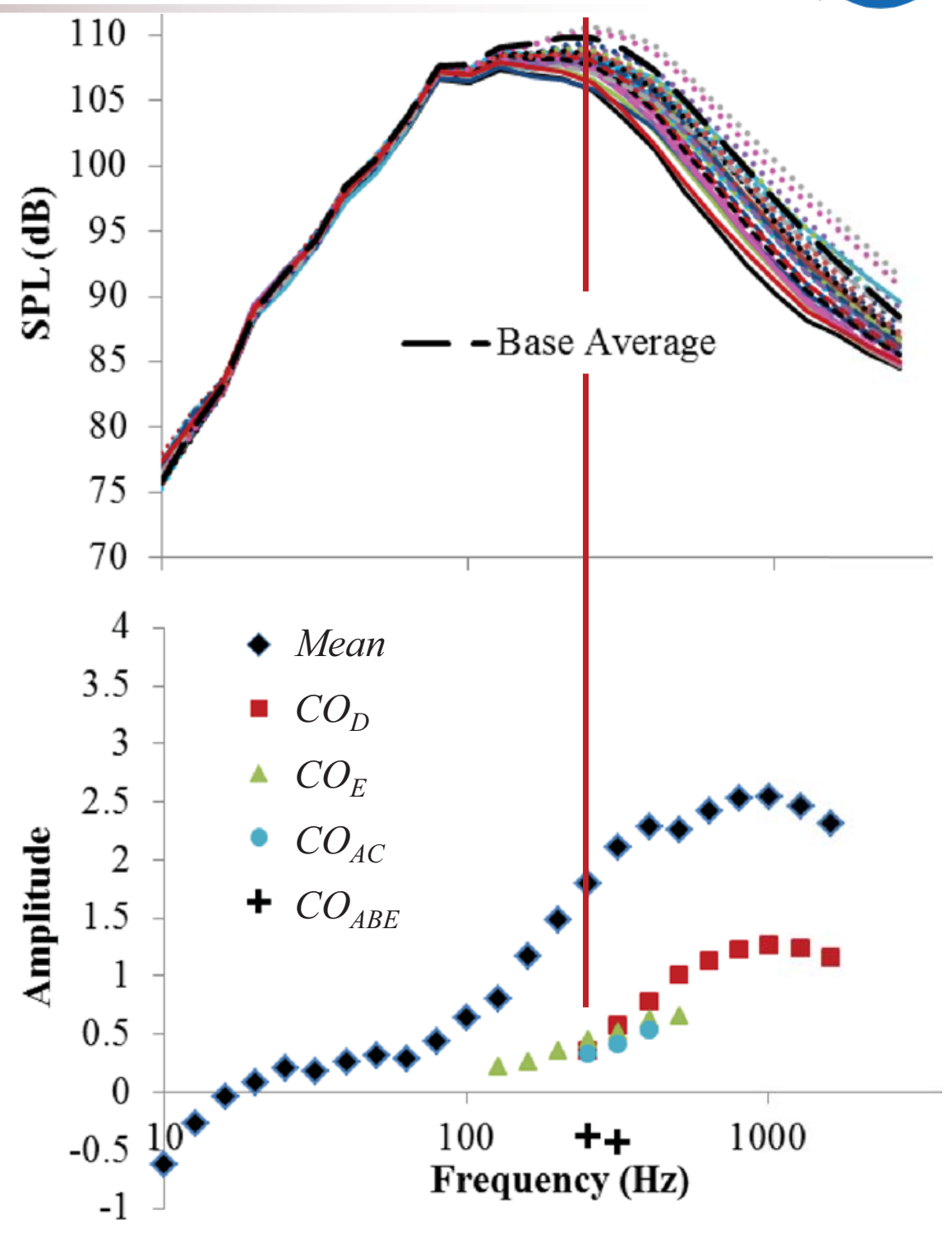

Main Effects

- Azimuthal Angle Bottom

- Trailing Edge Distance Interaction Effects

- AOA Top, Azimuthal Top

- AOA Top, AOA Bottom, Trailing Edge Distance 


\section{Sideline Model Comparison}
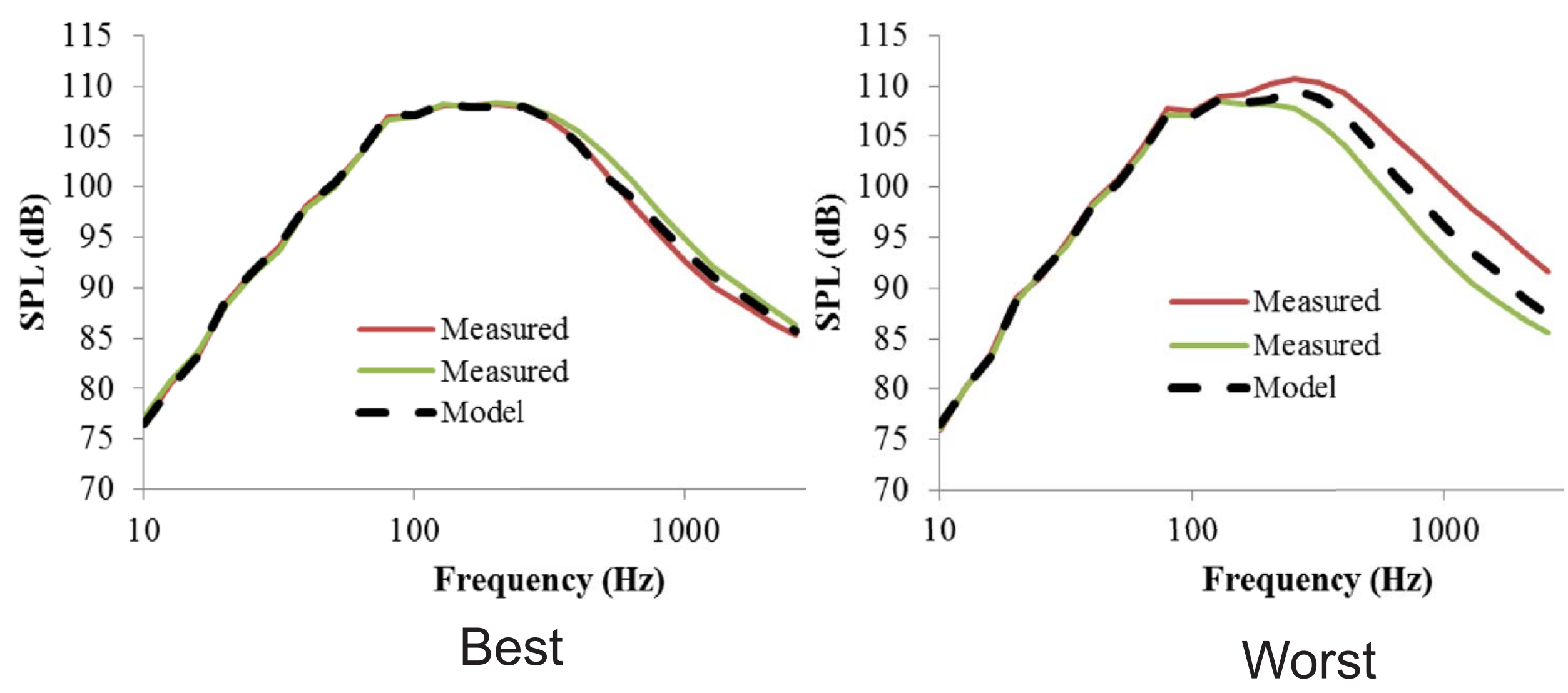

Differences in measured and modeled levels for all but one configuration are within data spread for center configurations 


\section{Sideline Model Comparison}

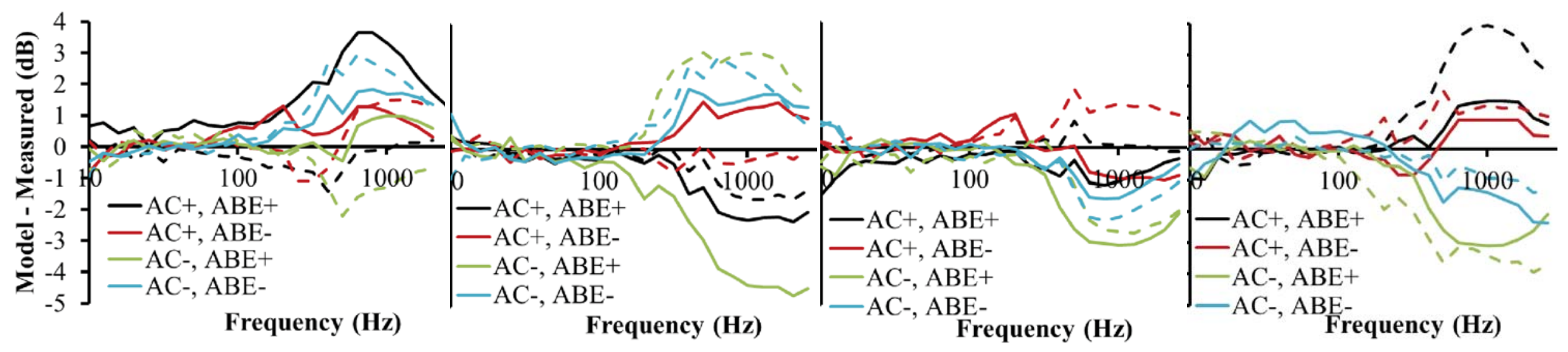




\section{Sideline Model Comparison - Center}

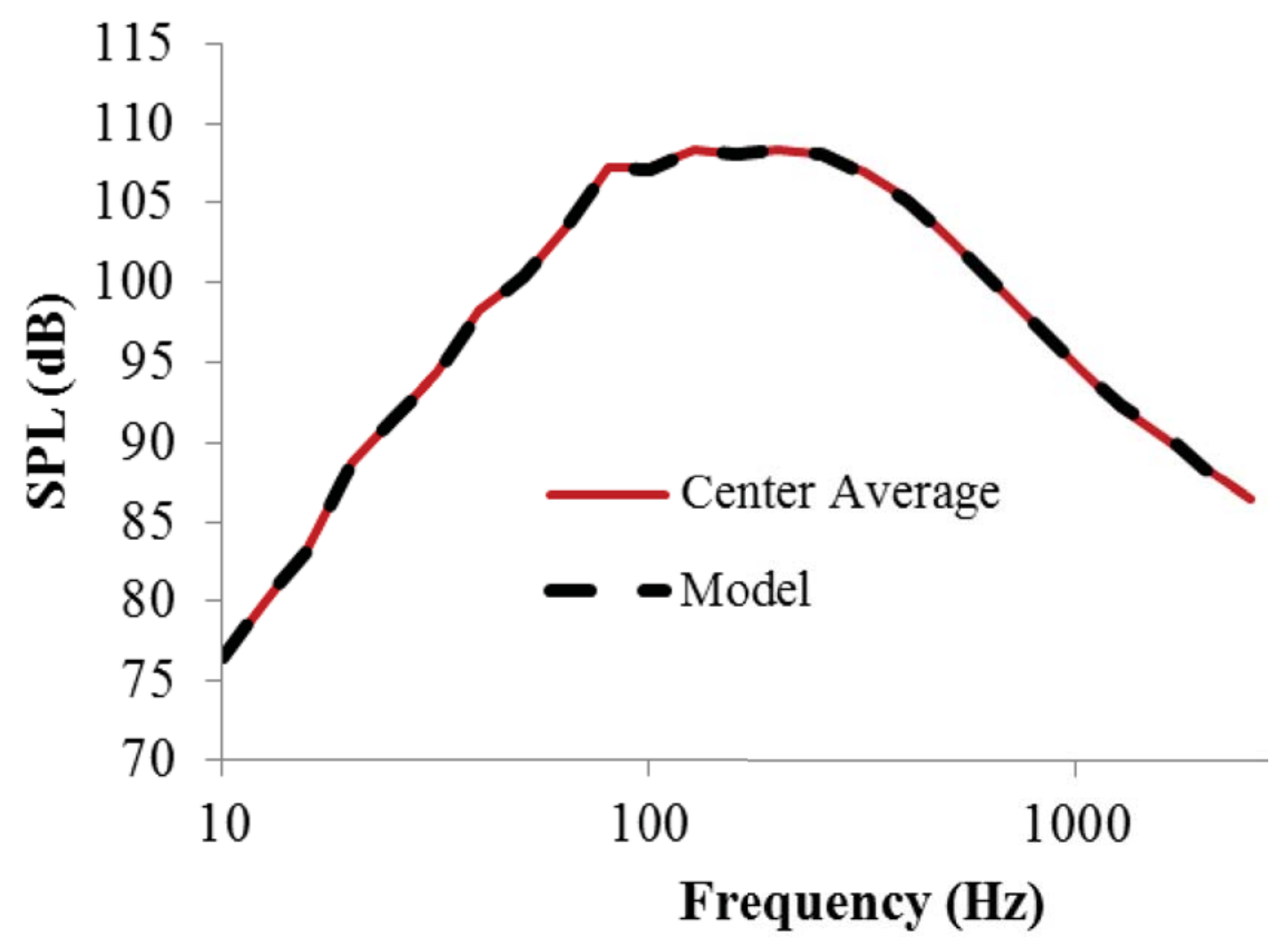

Model fits Center Point data - no curvature 


\section{Lower Model - Peak Polar Angle}

\begin{tabular}{|l|c|c|}
\hline \multicolumn{1}{|c|}{ Parameter } & $\begin{array}{c}\text { Low } \\
\text { Level }\end{array}$ & $\begin{array}{c}\text { High } \\
\text { Level }\end{array}$ \\
\hline AOA Top (A) & 5 & 10 \\
\hline AOA Bottom (B) & 5 & 10 \\
\hline Azimuthal Top (C) & 120 & 150 \\
\hline Azimuthal Bottom (D) & 60 & 90 \\
\hline $\begin{array}{l}\text { Trailing Edge } \\
\text { Distance (E) }\end{array}$ & -0.75 & -0.50 \\
\hline
\end{tabular}

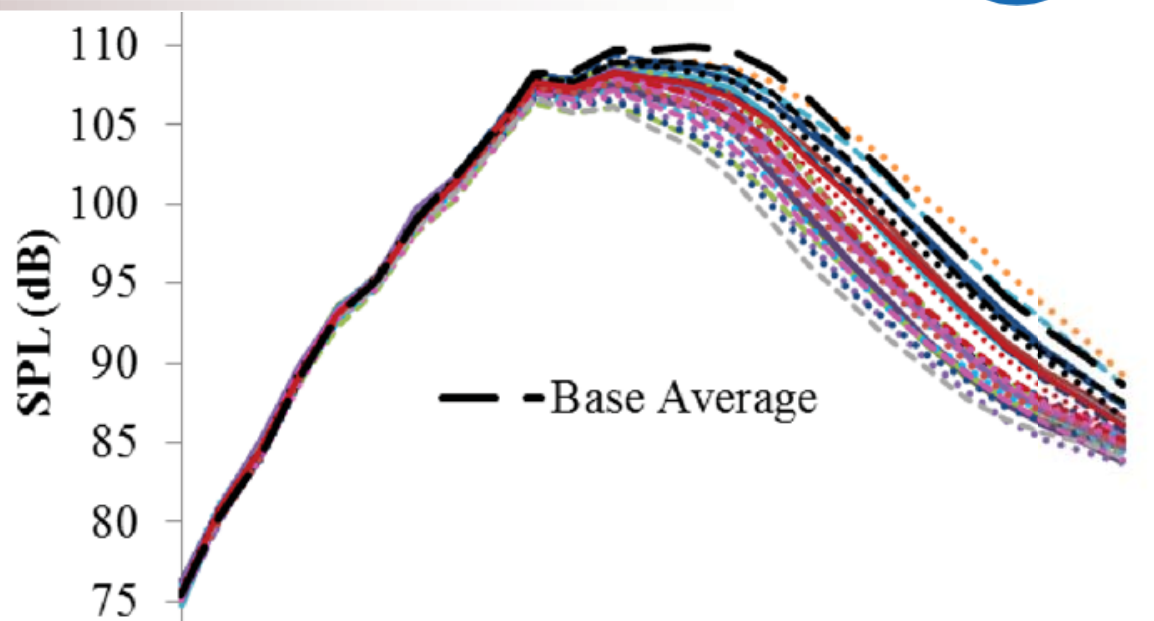

- AOA Bottom

- Azimuthal Angle Bottom

- Trailing Edge Distance Interaction Effects

- AOA Top, Azimuthal Angle Bottom

- Azimuthal Angle Top, Azimuthal Angle Bottom

- AOA Top, AOA Bottom, Trailing Edge Distance

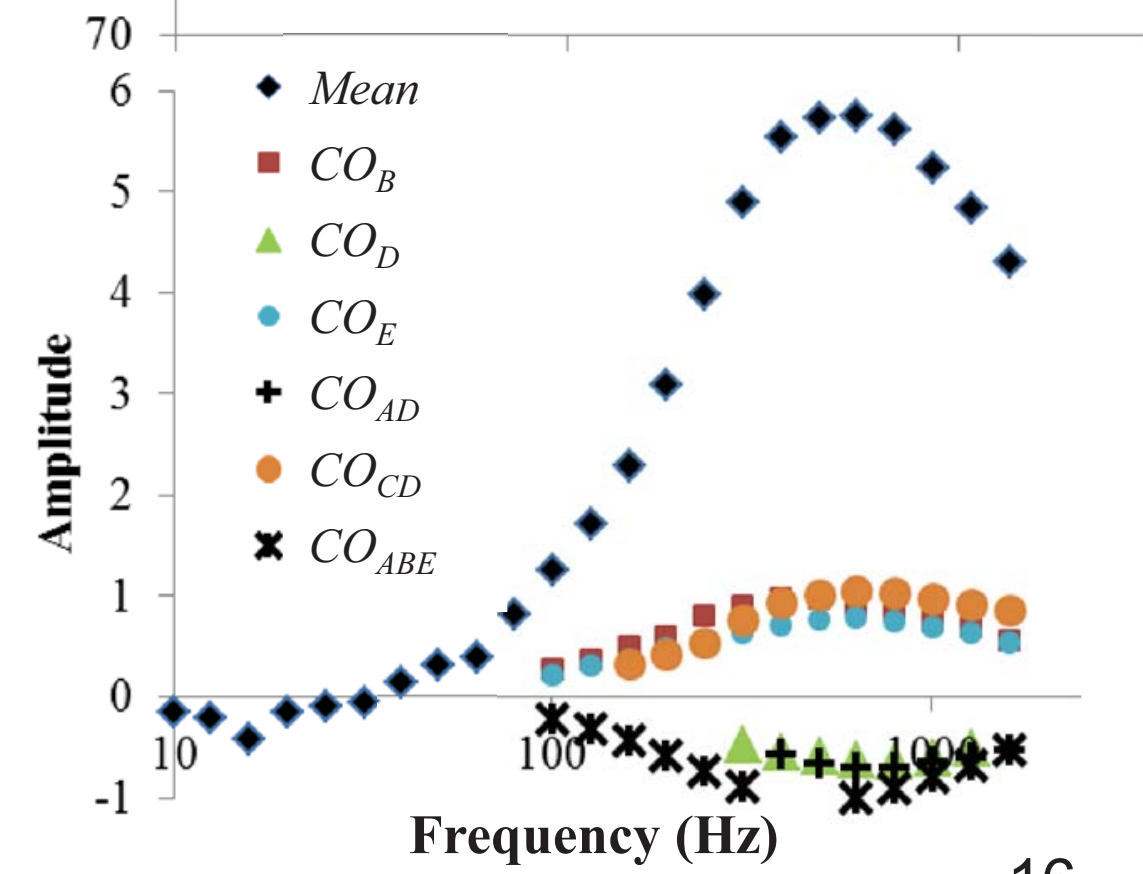




\section{Lower Model Comparison}
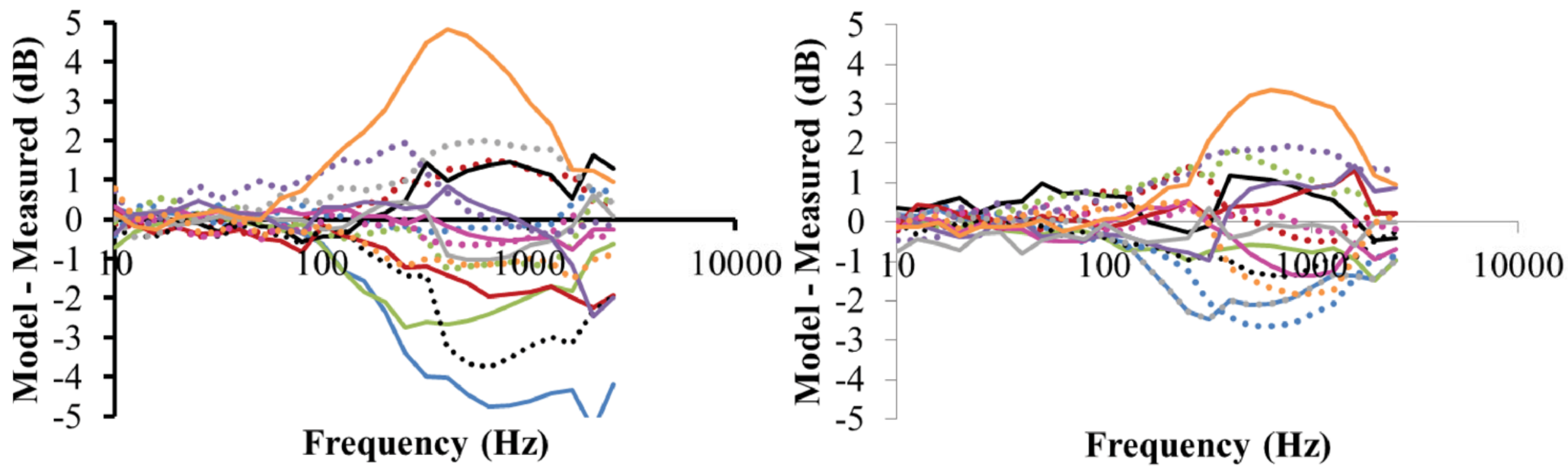

Differences in measured and modeled levels for all but two configuration are within data spread for center configurations 


\section{Lower Model Comparison - Center}

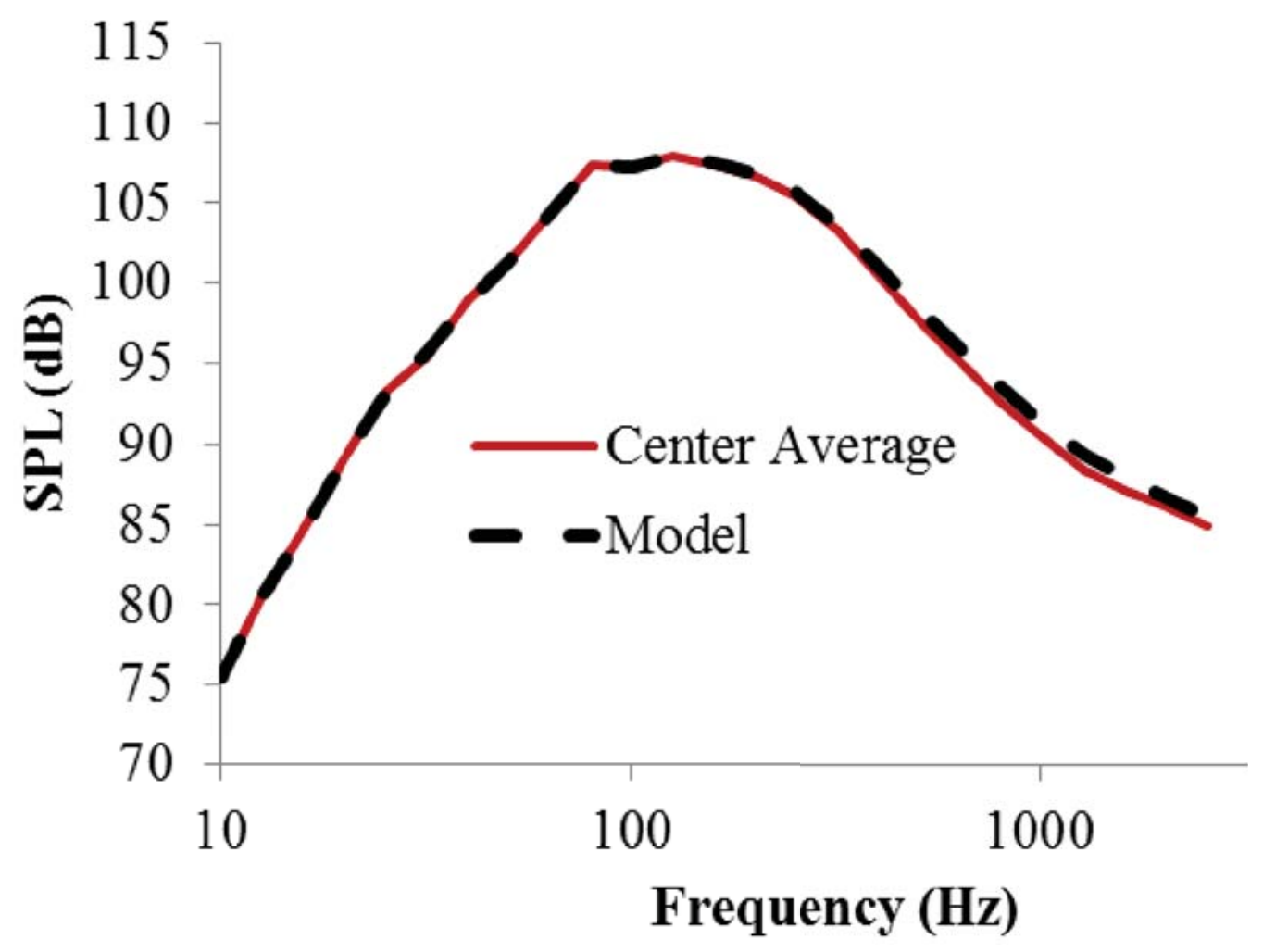

Model fits Center Point data - no curvature 


\section{Conclusions}

- Fan airfoil inserts reduce noise in the peak-jet-noise direction on the "thick" side of the fan stream

- Noise reduction for the Lower Array is greater than that for the Sideline Array

- Noise reduction is greater at high power settings than low power settings

- For the Sideline Array, bottom airfoil azimuthal angle has the greatest impact on mid- and low-frequency acoustic radiation

- For the Lower Array, bottom airfoil AOA and azimuthal angle as well as airfoil trailing edge distance impact mid- and highfrequency acoustic radiation

- Interaction terms are important in models developed for both azimuthal arrays

- Models are now available for NASA's Aircraft Noise Prediction Program (ANOPP) 


\section{Future Work}

- Optimized (for low noise) configuration will be determined from the models

- RANS solutions for the optimized design will be obtained

- Other techniques for obtaining the optimized flow-field will be investigated 